Tropical Journal of Pharmaceutical Research June 2019; 18 (6): 1297-1303

ISSN: $1596-5996$ (print); 1596-9827 (electronic)

(C) Pharmacotherapy Group, Faculty of Pharmacy, University of Benin, Benin City, 300001 Nigeria.

\title{
Fingerprint and multi-component quantitative analyses for quality evaluation of Rhizoma coptidis steamed with rice wine
}

\author{
Jin Wang ${ }^{1}$, Hai-rong Zeng ${ }^{1}$, Guan-hua Lou ${ }^{1}$, Chang-jiang $\mathrm{Hu}^{1}$, Qin-wan Huang ${ }^{1 \star}$, \\ Xiang-bo Yang ${ }^{2}$ \\ ${ }^{1}$ College of Pharmacy, Chengdu University of Traditional Chinese Medicine, Chengdu, ${ }^{2}$ Xunkang Pharm Ltd, Ya'an, China
}

*For correspondence: Email: hqwan2163@163.com

Sent for review: 10 October 2018

Revised accepted: 17 May 2019

\begin{abstract}
Purpose: To establish a method for the simultaneous determination of multi-components of Rhizoma coptidis steamed with rice wine (RCRW), and to provide a reference for assessing its standard of quality.

Method: Chromatographic separation was performed on a high performance liquid chromatography (HPLC) system to determine the characteristic fingerprint of RCRW. The mobile phase consisted of acetonitrile $(A)$ and $0.1 \%$ trifluoroacetic acid $(B)$, with gradients of $B$ as follows: $15-20 \%$ from $0-30$ min; 20 - $25 \%$ from 30 - $50 \mathrm{~min}$; 25 - $35 \%$ for 50 - $60 \mathrm{~min}$, and $35 \%$ for 60 - $70 \mathrm{~min}$.

Results: In the multiple reaction monitoring mode, eight components of RCRW were isolated by HPLCphoto-diode array (PDA) method. A fingerprint of the RCRW was established and 8 peaks were calibrated. The method was further validated in terms of linearity $\left(R^{2}>0.9993\right)$, precision (relative standard deviation, $R S D<1.51 \%)$; repeatability $(R S D<2.98 \%)$ and stability $(R S D<1.93 \%)$. Mean recovery rate ranged from 96.2 to $103.8 \%$, while $R S D$ values ranged from 0.92 to $2.88 \%$.

Conclusion: These results show that HPLC-PDA method is accurate and feasible, and that they provide a reference for further comprehensive and effective quality control of RCRW.
\end{abstract}

Keywords: Rhizoma coptidis, Rice wine, Fingerprint analysis, Chemical composition, Multi-conponent quantification, Quality evaluation

\begin{abstract}
This is an Open Access article that uses a fund-ing model which does not charge readers or their institutions for access and distributed under the terms of the Creative Commons Attribution License (http://creativecommons.org/licenses/by/4.0) and the Budapest Open Access Initiative (http://www.budapestopenaccessinitiative.org/read), which permit unrestricted use, distribution, and reproduction in any medium, provided the original work is properly credited.

Tropical Journal of Pharmaceutical Research is indexed by Science Citation Index (SciSearch), Scopus, International Pharmaceutical Abstract, Chemical Abstracts, Embase, Index Copernicus, EBSCO, African Index Medicus, JournalSeek, Journal Citation Reports/Science Edition, Directory of Open Access Journals (DOAJ), African Journal Online, Bioline International, Open-J-Gate and Pharmacy Abstracts
\end{abstract}

\section{INTRODUCTION}

Traditional Chinese medicines (TCM) refer to drugs produced under the guidance of Chinese medicinal theory. The compositions of these drugs are complex, but the effective active principles reside in one or more of these components [1,2]. Thus, it is difficult to accurately ascertain the internal comprehensive quality of TCM [3]. Therefore, quality control model for multi-component simultaneous determination has emerged as a quite important and indispensable tool for TCM's quality control $[4,5]$.

In Chinese Pharmacopoeia, Rhizoma coptidis $(\mathrm{RC})$ refers to the dry rhizomes of Coptis 
chinensis Franch, Coptisteeta Wall, or Coptis deltoidea C. Y. Cheng et Hsiao. Rhizoma coptidis is usually used for "clearing heat and dampness, and purging fire', and for detoxification". Pharmacological researches have revealed the beneficial effects of $R C$ in the treatment of sour regurgitation, diarrhea, jaundice, high fever and dizziness, insomnia, palpitation and restlessness [6]. Rhizoma coptidis steamed with rice wine (RCRW) is a processed product of RC which has a very good anti-diabetic effect $[7,8]$.

Studies have shown that berberrubine, a metabolite of berberine, is produced in RCRW [9]. Berberrubine possesses hypoglycemic [10], anti-tumor, and anti-inflammatory properties [11]. Studies have shown that RCRW improved insulin resistance in 3T3-L1 adipocytes, and enhanced the ability of adipocytes to take up glucose and use it to improve insulin resistance at the cellular level in vitro [12].

However, there are no studies so far on the quality control system of RCRW, and research on its composition is scanty [12]. Thus, it's important to set up a comprehensive quality control mean for the RCRW.

Multi-component quantitative analysis in combination with chromatographic fingerprint is an effective strategy for quality control of TCMs [13]. This technique is used in the quality control of Centipedae Herba [14], Yu-jin processed products [15], Bai Alba processed products [16], Radix scutellariae [17], and Rutaecarpine [18]. Thus, multi-component determination combined with fingerprint might be a feasible approach for the comprehensive quality control of RCRW. Consequently, the present study was carried out to establish a quality control method for RCRW using HPLC-PDA, based on fingerprint and simultaneous multi-component quantification of 8 components (Figure 1).
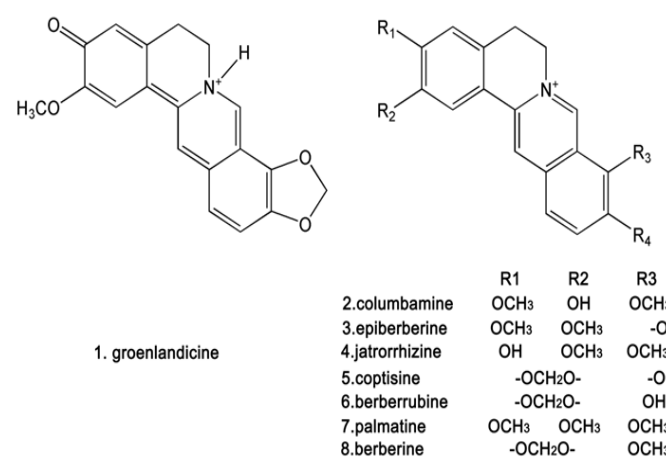

$\begin{array}{cccc}\mathrm{R} 1 & \mathrm{R} 2 & \mathrm{R} 3 & \mathrm{R} 4 \\ \mathrm{OCH}_{3} & \mathrm{OH} & \mathrm{OCH}_{3} & \mathrm{OCH}\end{array}$ $\mathrm{OCH}_{3} \quad \mathrm{OCH}_{3} \quad \mathrm{OCH}_{2}$ $\mathrm{OH} \quad \mathrm{OCH}_{3} \quad \mathrm{OCH}_{3} \quad \mathrm{OCH}_{3}$ $-\mathrm{OCH}_{2} \mathrm{O}-\quad-\mathrm{OCH}_{2} \mathrm{O}-$ $-\mathrm{OCH}_{2} \mathrm{O}-\quad \mathrm{OH} \quad \mathrm{OCH}$

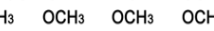

Figure 1: Chemical structures of the eight alkaloids in RCRW

\section{EXPERIMENTAL}

\section{Chemicals, reagents and samples}

Reference standards of groenlandicine (batch number: MUST-17110502), columbamine (batch number: MUST-17031901), epiberberine (batch number: $\quad$ MUST-072011), jatrorrhizine hydrochloride (batch number: MUST-17110702), coptisine chloride (batch number: MUST17061705), palmatine hydrochloride (batch number: MUST-17022604), and berberine hydrochloride (batch number: MUST-17110105) (purity $\geq 98 \%$ ) were purchased from the Chengdu Must Bio-Technology Co., Ltd. The reference standard of berberrubine (batch number: 16121302) (purity $\geq 98 \%$ ) was bought from Chengdu Pufei De Biotech., Ltd. Methanol and acetonitrile (Fisher Scientific) were of HPLC grade. Other reagents were of analytical purity. Liquid-phase water was made by superior-PU Ultra-Pure (UPH-I-10T, Chengdu Ultrapure Technology Co. Ltd).

Five 5 batches of RCRW samples used (S1-S5) were provided by the Xunkang Pharm. Ltd. (Ya'an, China), while 5 other batches of RCRW (S6-S10) were processed in our laboratory (State Administration of Traditional Chinese Medicine Research Laboratory). RC samples were obtained from Chengdu Hehuachi medicinal herbs market, and were identified by Professor Xianming Lu (detailed sample information is shown on Table 1). Compared with RC, the color of RCRW ranged from brownish to dark brown, and the appearance was rough, with tiny fibrous roots (Figure 2).

Table 1: Information on 10 batches of RCRW used

\begin{tabular}{|c|c|c|}
\hline Code & $\begin{array}{l}\text { Sample } \\
\text { information }\end{array}$ & Place of purchase \\
\hline S1 & Company made 1 & $\begin{array}{l}\text { Xunkang Pharm. Ltd. } \\
\text { (Ya'an, China) }\end{array}$ \\
\hline $\mathrm{S} 2$ & Company made 2 & $\begin{array}{l}\text { Xunkang Pharm. Ltd. } \\
\text { (Ya'an, China) }\end{array}$ \\
\hline S3 & Company made 3 & $\begin{array}{l}\text { Xunkang Pharm. Ltd. } \\
\text { (Ya'an, China) }\end{array}$ \\
\hline S4 & Company made 4 & $\begin{array}{l}\text { Xunkang Pharm. Ltd. } \\
\text { (Ya'an, China) }\end{array}$ \\
\hline S5 & Company made 5 & $\begin{array}{l}\text { Xunkang Pharm. Ltd. } \\
\text { (Ya'an, China) }\end{array}$ \\
\hline S6 & Laboratory made 1 & $\begin{array}{l}\text { Chengdu Hehuachi } \\
\text { medicinal herbs market }\end{array}$ \\
\hline S7 & Laboratory made 2 & $\begin{array}{l}\text { Chengdu Hehuachi } \\
\text { medicinal herbs market }\end{array}$ \\
\hline S8 & Laboratory made 3 & $\begin{array}{l}\text { Chengdu Hehuachi } \\
\text { medicinal herbs market }\end{array}$ \\
\hline S9 & Laboratory made 4 & $\begin{array}{l}\text { Chengdu Hehuachi } \\
\text { medicinal herbs market }\end{array}$ \\
\hline S10 & Laboratory made 5 & $\begin{array}{l}\text { Chengdu Hehuachi } \\
\text { medicinal herbs market }\end{array}$ \\
\hline
\end{tabular}



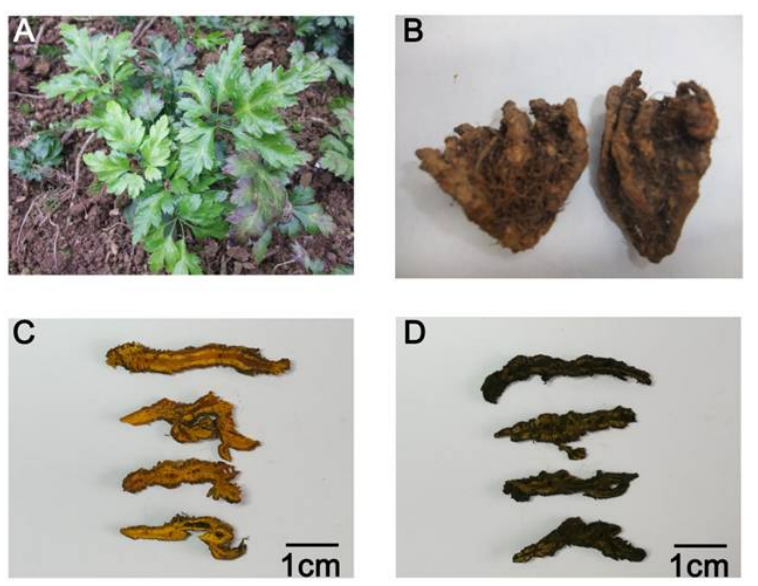

Figure 2: Original plant (Coptis chinensis Franch) (A); Original herbs (B); Rhizoma Coptidis (C), and Rhizoma Coptidis steamed with rice wine (D)

\section{Instrumentation and chromatographic conditions}

The HPLC analyses was performed using a Prominence-i LC-2030C 3D instrument equipped with a photo-diode array (PDA) detector, an auto sampler, a column heater, and a Welch Ultimate $\AA X B-C 18 \quad(250 \mathrm{~mm} \times 4.6 \mathrm{~mm}, 5 \mu \mathrm{m})$ column. The mobile phase consisted of acetonitrile $(A)$ and $0.1 \%$ trifluoroacetic acid $(B)$, with gradient of $B$ as follows: $15-20 \%$ from $0-$ $30 \mathrm{~min} ; 20$ - $25 \%$ from 30 - 50 min; 25 - $35 \%$ for $50-60 \mathrm{~min}$, and $35 \%$ for $60-70 \mathrm{~min}$. Column temperature was set at $25{ }^{\circ} \mathrm{C}$, while its flow rate was $1 \mathrm{~mL} / \mathrm{min}$. The injection volume was $10 \mu \mathrm{L}$, and $346 \mathrm{~nm}$ is the UV detection wavelength.

Under these chromatographic conditions, chromatographic peaks of the sample solution and reference solution were identical and had the same retention times. The degree of separation of groenlandicine, columbamine, epiberberine, jatrorrhizine hydrochloride, coptisine chloride, berberrubine, palmatine hydrochloride, and berberine hydrochloride were all greater than 1.5, the number of theoretical plates was greater than 60000 , and the negative reference substance showed no chromatographic peak in corresponding position. Thus, the method showed good specificity.

\section{Sample preparation}

The RCRW (0.2 g, sieved through a 60-mesh) was mixed with $50 \mathrm{~mL}$ of a solution of methanol and hydrochloric acid $(100: 1, \mathrm{v} / \mathrm{v})$. Then, it was processed ultrasonically for $30 \mathrm{~min}$, after weighing the flask. The solution was then filtered. The filtrate $(2 \mathrm{~mL})$ was put in a $10-\mathrm{mL}$ volumetric flask, and methanol was added to the tick mark, with shaking. The solution was filtered through a filter $(0.45 \mu \mathrm{m}$ pore size, Nylon) prior to injection.

\section{Preparation of standard solutions}

Methanol (HPLC grade) was used to prepare 25 $\mathrm{mL}$ of each of the standard compounds groenlandicine, columbamine, epiberberine, jatrorrhizine hydrochloride, coptisine chloride, berberrubine, palmatine hydrochloride, and berberine hydrochloride at concentrations of $1.36,7.12,0.643,4.176,18.33,0.515,15.708$ and $58.32 \mu \mathrm{g} / \mathrm{mL}$. The standard solutions were kept at $4{ }^{\circ} \mathrm{C}$ prior to analysis.

\section{Validation of HPLC method}

Linearity was surveyed and evaluated using serial concentrations of the standard solutions of the eight components. Using the chromatographic conditions stated earlier, the peak areas of mixed standard solutions were determined with sample volumes of $1,2,4,6,8$, 10,15 and $20 \mu \mathrm{L}$. The calibration curves were constructed by plotting peak area against concentration. From the standard curve, regression equations were derived using the reference quantity of the control sample as the horizontal axis $(x)$ and the peak area of the chromatogram as the ordinate $(\mathrm{y})$. The limit of detection (LOD) and limit of quantification (LOQ) were the corresponding concentrations at signalto-noise ratios of $3: 1$ and 10:1, respectively.

Precision was assessed by repeating six measurements of the same mixed reference solution with a sample volume of $10 \mu \mathrm{L}$. The RSD values were calculated from the peak areas of groenlandicine, columbamine, epiberberine, jatrorrhizine hydrochloride, coptisine chloride, berberrubine, palmatine hydrochloride and berberine hydrochloride.

Repeatability was obtained from six replicated determinations of the sample (sample 1) solution with sample volume of $10 \mu \mathrm{L}$. The RSD values were calculated based on the mass fraction of groenlandicine, columbamine, epiberberine, jatrorrhizine hydrochloride, coptisine chloride, berberrubine, palmatine hydrochloride and berberine hydrochloride.

Stability was tested with $10 \mu \mathrm{l}$ of each sample solution kept at room temperature for different durations i.e. $0,2,4,6,8,1,12,16$ and $24 \mathrm{~h}$ after preparation, and the RSD values were calculated.

Six samples (S1, $0.1 \mathrm{~g}$ ), determined already, were weighed. Then $1 \mathrm{~mL}$ standard solution in 
which the concentrations of the eight compounds were $0.2125,0.6675,0.150,0.475,2.225$, $0.08125,2.025$, and $2.625 \mathrm{mg} / \mathrm{mL}$, respectively, was added. Using the above method of sample preparation, the peak areas of the mixed standard solution were determined with the sample size of $10 \mu \mathrm{L}$, and the rate of recovery (R) was obtained. Estimating the average recovery based on the following formula:

$R(\%)=[($ Af-Of $) / A s] 100$

where $A f$ is the actual measured content, Of is the theoretical material content, and As is the amount of standard.

\section{RESULTS}

The HPLC chromatograms of mixed standards, sample and negative reference compound are shown in Figure 3.

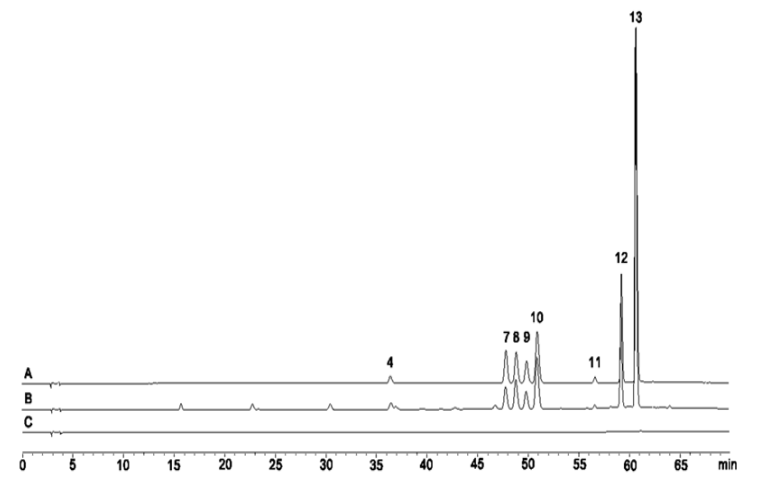

Figure 3: HPLC chromatograph of reference compounds (A), sample (B) and negative reference substance $(C)$. (4: groenlandicine, 7: Columbamine, 8: epiberberine, 9: jatrorrhizine hydrochloride, 10: coptisine chloride, 11: berberrubine, 12: palmatine hydrochloride, and 13: berberine hydrochloride)

To confirm the most effective extraction procedure with the highest yields of the eight compounds, different extraction parameters i.e. extraction methods (ultrasonic, and reflux), extraction solvents (methanol, methanol: hydrochloric acid (100:1, v:v), methanolhydrochloric acid (100:3, v:v), $70 \%$ methanol, 70 $\%$ methanol: hydrochloric acid (100:1, v:v)), volume of solvent $(30,50$ and $70 \mathrm{~mL})$, and extraction time $(15,30$ and $45 \mathrm{~min})$ were examined and optimized.

Ultrasonic extraction with $50 \mathrm{~mL}$ of methanol: hydrochloric acid (100:1, v:v) for 30 min was selected as the best extraction condition. Furthermore, different types of columns were investigated. The Welch Ultimate®XB-C18 (250 $\mathrm{mm} \times 4.6 \mathrm{~mm}, 5 \mathrm{~mm}$ ) column, which allowed for providing the widest range of usable $\mathrm{pH}(\mathrm{pH}$ 210), was selected. Aqueous solutions of acetonitrile and $0.1 \%$ trifluoroacetic acid were the most suitable eluents for gradient elution because they resulted in satisfactory resolutions and fairish peak parameters.

The linearity results for the eight components are shown in Table 2. The data showed a good linear correlation $\left(R^{2}>0.9993\right)$. The LOD and LOQ values ranged from 0.03 to $0.54 \mathrm{ng}$, and 0.11 to $1.90 \mathrm{ng}$, respectively.

In the precision test, the RSD values of the peak areas of the eight components ranged from 0.88 to $1.51 \%$, which indicated that the instrument had high precision, and in the repeatability test, the RSD values of each compound were less than $2.98 \%$, indicating the method had good repeatability. In the stability test, the RSD values of the compounds ranged from 0.99 to $1.93 \%$, suggesting that the eight compounds were stable within $24 \mathrm{~h}$. With regard to the recovery results, the average recovery rates were between 96.97 and $103.01 \%$, with RSD values ranging from 0.92 to $2.88 \%$. These results are shown in Table 3 and Table 4.

From the results of characteristic pattern analysis of 10 batches of samples, there were 13 common characteristic peaks in RCRW (Figure 4). Eight of these peaks were identified by comparing with the standard compounds.

Table 2: Calibration curves, LOD and LOQ of the investigated compounds

\begin{tabular}{llllll}
\hline Compound & Regression equation & Linear range & $\mathbf{R}^{2}$ & $\begin{array}{l}\text { LOD } \\
(\mathbf{n g})\end{array}$ & $\begin{array}{l}\text { LOQ } \\
(\mathbf{n g})\end{array}$ \\
\hline Groenlandicine & $\mathrm{y}=5241366.6960 x-2320.6343$ & $1.36-27.20$ & $\mathrm{R}^{2}=0.9993$ & 0.54 & 1.90 \\
Columbamine & $\mathrm{y}=4551141.9960 x-402.8308$ & $7.12-142.40$ & $\mathrm{R}^{2}=0.9999$ & 0.12 & 0.39 \\
Epiberberine & $\mathrm{y}=48318782.5900 x-608.9129$ & $0.64-12.86$ & $\mathrm{R}^{2}=0.9999$ & 0.03 & 0.11 \\
Jatrorrhizine hydrochloride & $\mathrm{y}=5341672.4650 x-516.5498$ & $4.18-83.52$ & $\mathrm{R}^{2}=0.9999$ & 0.12 & 0.40 \\
Coptisine chloride & $\mathrm{y}=3058012.4930 x-916.1692$ & $18.33-366.60$ & $\mathrm{R}^{2}=0.9999$ & 0.14 & 0.46 \\
Berberrubine & $\mathrm{y}=8319926.0740 x-475.0846$ & $0.52-10.29$ & $\mathrm{R}^{2}=0.9997$ & 0.20 & 0.78 \\
Palmatine hydrochloride & $\mathrm{y}=4177409.4220 x+3913.239115 .71-314.16$ & $\mathrm{R}^{2}=0.9999$ & 0.07 & 0.25 \\
Berberine hydrochloride & $\mathrm{y}=3860587.4720 x+5614.485258 .32-1166.40$ & $\mathrm{R}^{2}=0.9999$ & 0.05 & 0.19 \\
\hline
\end{tabular}


Table 3: Recovery in the HPLC method for determination of 4 of the compounds

\begin{tabular}{|c|c|c|c|c|c|c|}
\hline Compound & $\begin{array}{l}\text { Original found } \\
\text { (mg) }\end{array}$ & $\begin{array}{l}\text { Amount spiked } \\
(\mathrm{mg})\end{array}$ & $\begin{array}{l}\text { Amount found } \\
(\mathrm{mg})\end{array}$ & Recovery (\%) & $\begin{array}{l}\text { Mean } \\
\text { recovery (\%) }\end{array}$ & RSD (\%) \\
\hline \multirow{6}{*}{ Groenlandicine } & 0.17 & 0.21 & 0.39 & 103.64 & \multirow{6}{*}{101.38} & \multirow{6}{*}{2.88} \\
\hline & 0.18 & 0.21 & 0.40 & 104.45 & & \\
\hline & 0.18 & 0.21 & 0.40 & 103.69 & & \\
\hline & 0.17 & 0.21 & 0.38 & 97.44 & & \\
\hline & 0.16 & 0.21 & 0.38 & 99.06 & & \\
\hline & 0.17 & 0.21 & 0.38 & 100.01 & & \\
\hline \multirow{6}{*}{ Columbamine } & 0.61 & 0.67 & 1.27 & 99.06 & \multirow{6}{*}{97.60} & \multirow{6}{*}{2.23} \\
\hline & 0.63 & 0.67 & 1.26 & 95.22 & & \\
\hline & 0.62 & 0.67 & 1.26 & 95.60 & & \\
\hline & 0.62 & 0.67 & 1.29 & 100.81 & & \\
\hline & 0.60 & 0.67 & 1.25 & 96.54 & & \\
\hline & 0.61 & 0.67 & 1.26 & 98.35 & & \\
\hline \multirow{6}{*}{ Epiberberine } & 0.08 & 0.15 & 0.23 & 103.54 & \multirow{6}{*}{102.64} & \multirow{6}{*}{1.05} \\
\hline & 0.08 & 0.15 & 0.23 & 103.42 & & \\
\hline & 0.08 & 0.15 & 0.23 & 102.77 & & \\
\hline & 0.08 & 0.15 & 0.23 & 103.21 & & \\
\hline & 0.08 & 0.15 & 0.23 & 102.23 & & \\
\hline & 0.07 & 0.15 & 0.22 & 100.68 & & \\
\hline \multirow{6}{*}{$\begin{array}{l}\text { Jatrorrhizine } \\
\text { hydrochloride }\end{array}$} & 0.41 & 0.48 & 0.88 & 99.40 & \multirow{6}{*}{97.15} & \multirow{6}{*}{1.60} \\
\hline & 0.42 & 0.48 & 0.88 & 95.97 & & \\
\hline & 0.42 & 0.48 & 0.88 & 96.99 & & \\
\hline & 0.40 & 0.48 & 0.87 & 97.18 & & \\
\hline & 0.41 & 0.48 & 0.87 & 98.27 & & \\
\hline & 0.39 & 0.48 & 0.85 & 95.07 & & \\
\hline
\end{tabular}

Table 4: Recovery in the HPLC method for determination of 4 of the compounds

\begin{tabular}{|c|c|c|c|c|c|c|}
\hline Compound & $\begin{array}{l}\text { Original found } \\
\text { (mg) }\end{array}$ & $\begin{array}{l}\text { Amount spiked } \\
(\mathrm{mg})\end{array}$ & $\begin{array}{l}\text { Amount found } \\
(\mathrm{mg})\end{array}$ & Recovery (\%) & $\begin{array}{c}\text { Mean } \\
\text { recovery (\%) }\end{array}$ & RSD (\%) \\
\hline \multirow{6}{*}{$\begin{array}{l}\text { Coptisine } \\
\text { chloride }\end{array}$} & 2.31 & 2.23 & 4.47 & 97.30 & \multirow{6}{*}{97.01} & \multirow{6}{*}{1.56} \\
\hline & 2.36 & 2.23 & 4.54 & 97.61 & & \\
\hline & 2.34 & 2.23 & 4.55 & 99.46 & & \\
\hline & 2.26 & 2.23 & 4.41 & 96.55 & & \\
\hline & 2.28 & 2.23 & 4.42 & 96.08 & & \\
\hline & 2.21 & 2.23 & 4.32 & 95.04 & & \\
\hline \multirow{6}{*}{ Berberrubine } & 0.04 & 0.08 & 0.12 & 101.44 & \multirow{6}{*}{100.94} & \multirow{6}{*}{0.92} \\
\hline & 0.04 & 0.08 & 0.12 & 102.47 & & \\
\hline & 0.04 & 0.08 & 0.12 & 100.56 & & \\
\hline & 0.04 & 0.08 & 0.12 & 99.78 & & \\
\hline & 0.04 & 0.08 & 0.12 & 100.95 & & \\
\hline & 0.04 & 0.08 & 0.12 & 100.42 & & \\
\hline \multirow{6}{*}{$\begin{array}{l}\text { Palmatine } \\
\text { hydrochloride }\end{array}$} & 1.93 & 2.03 & 3.92 & 98.06 & \multirow{6}{*}{96.97} & \multirow{6}{*}{1.61} \\
\hline & 1.98 & 2.03 & 3.92 & 95.73 & & \\
\hline & 1.97 & 2.03 & 3.90 & 95.57 & & \\
\hline & 1.96 & 2.03 & 3.97 & 99.56 & & \\
\hline & 1.90 & 2.03 & 3.84 & 96.13 & & \\
\hline & 1.91 & 2.03 & 3.87 & 96.77 & & \\
\hline \multirow{6}{*}{$\begin{array}{l}\text { Berberine } \\
\text { hydrochloride }\end{array}$} & 8.08 & 2.63 & 10.80 & 103.41 & \multirow{6}{*}{103.01} & \multirow{6}{*}{1.11} \\
\hline & 8.02 & 2.63 & 10.68 & 101.58 & & \\
\hline & 7.74 & 2.63 & 10.46 & 103.33 & & \\
\hline & 7.81 & 2.63 & 10.56 & 104.88 & & \\
\hline & 7.55 & 2.63 & 10.24 & 102.32 & & \\
\hline & 7.71 & 2.63 & 10.41 & 102.53 & & \\
\hline
\end{tabular}

Peak 4 was groenlandicine, and peaks 7 - 13 were identified as columbamine, epiberberine, jatrorrhizine hydrochloride, coptisine chloride, berberrubine, palmatine hydrochloride and berberine hydrochloride, respectively. The regularities of these characteristic peaks were relatively strong and had good consistency, and they could be used as an effective quality evaluation method for RCRW. The characteristic fingerprint established had strong specificity, and was of reference significance for the identification of RCRW.

The results of HPLC-PDA quantitative assays for the 10 batches of samples are shown in Table 5 . In the RCRW, the average contents of berberine and coptisine chloride were 7.69 and $2.46 \%$, respectively. The changes in contents may be due to processing. 
Table 5: Contents of the 10 batches of RCRW

\begin{tabular}{|c|c|c|c|c|c|c|c|c|}
\hline No. & $\begin{array}{c}\text { Groenlandicine } \\
(\mathrm{mg} / \mathrm{g})\end{array}$ & $\begin{array}{c}\text { Columbamine } \\
(\mathrm{mg} / \mathrm{g})\end{array}$ & $\begin{array}{c}\text { Epiberberine } \\
(\mathrm{mg} / \mathrm{g})\end{array}$ & $\begin{array}{l}\text { Jatrorrhizine } \\
\text { Hydrochloride } \\
\text { (mg/g) }\end{array}$ & $\begin{array}{l}\text { Coptisine } \\
\text { chloride } \\
(\mathrm{mg} / \mathrm{g})\end{array}$ & $\begin{array}{c}\text { Berberrubine } \\
(\mathrm{mg}))\end{array}$ & $\begin{array}{c}\text { Palmatine } \\
\text { hydrochloride } \\
(\mathrm{mg})\end{array}$ & $\begin{array}{c}\text { Berberine } \\
\text { hydrochloride } \\
(\mathrm{mg} / \mathrm{g})\end{array}$ \\
\hline$\overline{\mathrm{S} 1}$ & 1.79 & 6.38 & 0.80 & 4.35 & 24.15 & 0.43 & 20.25 & 82.41 \\
\hline S3 & 1.84 & 5.13 & 1.02 & 3.85 & 26.92 & 0.13 & 18.05 & 80.74 \\
\hline S4 & 1.39 & 4.99 & 0.70 & 3.62 & 20.72 & 0.10 & 16.61 & 73.01 \\
\hline S5 & 1.41 & 5.16 & 0.70 & 3.66 & 22.02 & 0.21 & 16.34 & 69.38 \\
\hline S8 & 1.77 & 5.54 & 0.89 & 4.13 & 25.72 & 0.10 & 17.68 & 72.66 \\
\hline S9 & 1.79 & 6.31 & 0.87 & 4.19 & 24.55 & 0.36 & 20.07 & 81.32 \\
\hline S10 & 1.62 & 5.82 & 0.76 & 3.95 & 22.33 & 0.29 & 19.01 & 76.58 \\
\hline
\end{tabular}

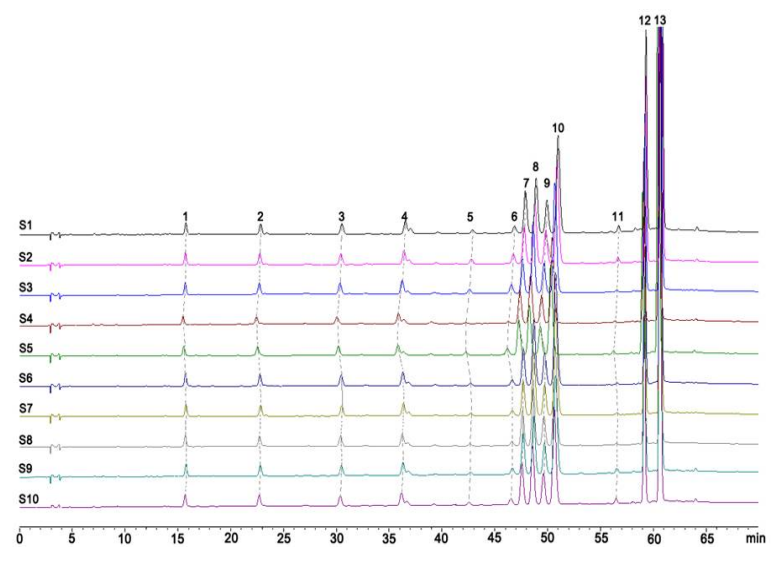

Figure 4: Standardized characteristic fingerprints of RCRW (S1 - S10)

\section{DISCUSSION}

The use of HPLC-ELSD, HPLC and UPLC-PAD as a means of quality control of RC have been reported [19-23]. In the 2015 edition of the Chinese Pharmacopoeia and Hong Kong Chinese standards, the quality control of $\mathrm{RC}$ used 4 and 2 components as quality control indicators, respectively. At present, the quality control of RCRW is based on RC, but studies on RCRW lack deep specificity. Moreover, there are no investigations on simultaneous determination of groenlandicine, columbamine, epiberberine, jatrorrhizine hydrochloride, coptisine chloride, berberrubine, palmatine hydrochloride, and berberine hydrochloride in RCRW. Thus, it is very necessary to study the standard of quality of RCRW.

In the present study, the HPLC-PDA method was used to analyze the quality of 8 components of RCRW from the point of view of fingerprint and multi-component quantification, and a method of simultaneous determination of multiple components was established, which was simple and reproducible. The use of the eight alkaloids was based on reports from relevant literature on the high activity components found on related websites. These compounds can serve as reference for assessing the standard of quality of RCRW.

\section{CONCLUSION}

A characteristic HPLC fingerprint of RCRW has been successfully established with simultaneous content determination of 8 constituents (groenlandicine, columbamine, epiberberine, jatrorrhizine hydrochloride, coptisine chloride, berberrubine, palmatine hydrochloride and berberine hydrochlorid). The established method is simple, rapid and accurate. It has both qualitative and quantitative applications, and it provides a scientific basis for effective quality control of RCRW.

\section{DECLARATIONS}

\section{Acknowledgement}

This work was financially supported by the project of administration of Traditional Chinese Medicine of Sichuan province (code: 2018JC011).

\section{Conflict of interest}

No conflict of interest is associated with this work.

\section{Contribution of authors}

We declare that this work was done by the authors named in this article and all liabilities pertaining to claims relating to the content of this article will be borne by the authors. JW and HRZ contributed equally as first authors. All authors read and approved the final manuscript for publication. 


\section{Open Access}

This is an Open Access article that uses a funding model which does not charge readers or their institutions for access and distributed under the terms of the Creative Commons Attribution License (http://creativecommons.org/licenses/by/ 4.0) and the Budapest Open Access Initiative (http://www.budapestopenaccessinitiative.org/rea d), which permit unrestricted use, distribution, and reproduction in any medium, provided the original work is properly credited.

\section{REFERENCES}

1. She YM, Hu YH, Han LY, Liu SX, Chen CP. Research progress on quality control of Chinese materia medica. Chin Tradit Herb Drugs 2017; 48: 2557-2563.

2. Wu WY, Guo DA. Strategies for elaboration of comprehensive quality standard system on traditional Chinese medicine. Chin J Chin Mater Med 2014; 39: 351-356.

3. Li LL, LV YF, Zhu $X Y$. Determination of multiple components in Gegen Qinlian tablets. Chin J Pharm Anal 2017; 37: 1607-1614.

4. Xu BX, Yang MY, Du YL, Zhao SN, Li YR, Pan HF. Fingerprint and multi-ingredient quantitative analyses for quality Evaluation of hawthorn leaves and Guang hawthorn leaves by UPLC-MS. Rev Bras Farmacog 2018; 28: 369-373.

5. Zhao JW, Qu LH, LiU YJ, Li SQ, Xu YY, Xiao L. Multicomponent Content Determination Combined with UPLC Fingerprints and Its Pattern Discrimination Evaluation of Scutellaria baicalensis Pith-nodecayed and Scutellaria baicalensis Pith-decayed. J Chin Med Mater 2017; 9: 2101-2106.

6. Meng FC, Wu ZF, Yin ZQ, Lin LG, Wang RB, Zhang QW. Coptidis rhizoma and its main bioactive components: recent advances in chemical investigation, quality evaluation and pharmacological activity. Chin Med 2018; 13: 1-18.

7. Li JC. The systemic study of JiuZhengHuangLian in diabetes based on the Literature of Materia Medica. Chengdu University of TCM. 2011.

8. Zheng HJ. Research on processing technology and quality evaluation of Rhizoma Coptidis steamed with rice wine. Chengdu University of TCM. 2010.

9. Wang J, Ran Q, Zeng HR., Wang L, Hu CJ, Huang QW. Cellular stress response mechanisms of Rhizoma coptidis: a systematic review. Chin Med 2018; 13: 1-13.

10. Li CJ, Hou SZ, Su ZR. Progress on Pharmacological Effects of Berberrubine. Pro Veter Med 2016; 37: 102104.

11. Yang $N$, Sun RB, Zhao YQ, He J, Zhen L, Guo JH, Geng $J L$, Xie $Y$, Wang JK, Feng $S Q$ et all. High fat diet aggravates the nephrotoxicity of berberrubine by influencing on its pharmacokinetic profile. Environ Toxicol Pharmacol 2016; 46: 319-327.

12. Li JC, Meng XL, Lai XR, Fan XJ, Zeng Y, Zhou XL. Comparative study on the pharmacodynamics of different coptis products and "Stop Diabetes" based on 3T3-L1 cells. Pharmacol Clin Chin Mater Clin Med 2010; 2: $52-54$.

13. Fan G, Zheng HJ, Lai XR, Geng ZP, Zhang Y. Study on the HPLC fingerprint of Rhizoma Coptidis steamed with rice wine and the comparison of different processed products. Pharm Clin Chin Mater Med 2011; 2: 20-23.

14. Zhang LJ, Dai HR, Fan Q, Xia PF, Yao J, Li Y. HPLC Fingerprints Analysis of Aconitum sinomontanum from Different Areas and Content Determination of Two Alkaloids. Chin J Exper Tradition Med 2017; 23: 41-46.

15. Zan K, Xie Y, Guo LN, Zheng J, Ma SC. Study on characteristic chromatogram and quantitation method of seven components for Centipedae Herba. Chin J Pharm Anal 2018; 38: 151-157.

16. Hao M, Lu TL, Mao CQ, Ji D, Li L, Su LL, Gu LY, Li P, Qin SR. UPLC Fingerprint and Multi-components determination of three processed products of Rhizome of curcuma wenyujin. Chin J Chin Mater Med 2018; 43: 2288-2294.

17. Zhao $Y Y$, Liang $D Q$, Jin $C S$, Wei $Q H$, Zhang $W$, $X u F Q$, Wang L. Determination of 7 Components in Standard Decoction of Different Processed Products of Paeoniae Alba Radix in Bozhou Based on HPLC Fingerprint Analysis. Nat Prod Res Dev 2018; 30: 404-411+500.

18. Li EZ, Liu YF, Liu YJ, Jiang S, Wang YN. Simultaneous determination of six components in Scutellaria baicalensis Georgi from different districts by HPLC. Chin Hosp Pharm J 2018; 38: 946-948.

19. Zhao JJ, Chen XM, Zheng SN, Zhai JL, Zhang R. HPLC Fingerprints Integrated with Quantitative Determination of Multi-components for Quality Control of Evodia rutaecarpa. Res Med J Res Prac 2015; 29: 62-65.

20. Kong WJ, Li ZL, Xiao XH, Zhao YL. Quality control for Coptidis rhizoma through the determination of five alkaloids by HPLC-ELSD coupled with chemometrics. Nat Prod Res 2010; 24: 1616-1129.

21. Li JY, Wang XB, Luo JG, Kong LY. Seasonal Variation of Alkaloid Contents and Anti-Inflammatory Activity of Rhizoma coptidis based on Fingerprints Combined with Chemometrics Methods. J Chromatogr Sci 2015; 53: 1131-1139.

22. Lv XM, Li Y, Tang C, Zhang $Y$, Zhang J, Fan G. Integration of HPLC-based fingerprint and quantitative analyses for differentiating botanical species and geographical growing origins of Rhizoma coptidis. Pharma Biol 2016; 54: 3264-3271.

23. Kong WJ, Zhao YL, Xiao XH, Jin C, Li ZL. Quantitative and chemical fingerprint analysis for quality control of rhizome Coptidischinensis based on UPLC-PAD combined with chemometrics methods. Phytomedicine 2009; 16: 950-959. 